\title{
Karyotype and RAPD Analysis of Male and Female Coccinia grandis L. from Bangladesh
}

\author{
Md. Uzzal Hossain, Mousona Islam, Mahin Afroz, \\ Syeda Sharmeen Sultana and Sheikh Shamimul Alam*
}

Department of Botany, University of Dhaka, Dhaka-1000, Bangladesh

Received January 2, 2016; accepted June 25, 2016

\begin{abstract}
Summary Both male and female Coccinia grandis L. were studied cytogenetically using conventional and fluorochrome dyes. In addition, RAPD was carried out to distinguish the two sexes. In male plants, a pair of prominent satellites was observed, one in each member of pair III. Both male and female plants were found to possess $2 n=24$ metacentric chromosomes (including "Y-chromosome"). The length of individual chromosomes ranged from 0.97 to $5.03 \mu \mathrm{m}$ (Y-chromosome) in the male and 0.78 to $1.32 \mu \mathrm{m}$ in the female plant. The Y-chromosome found in this study was $5.03 \mu \mathrm{m}$, which is about 3.06 times bigger than the largest autosome. The interphase nuclei of male specimens possessed a number of thick, round and darkly stained heterochromatic blocks. A bigger and elongated area was also observed in the interphase nuclei of male plants, which indicated the probable appearance of heterochromatic Y-chromosome. A distinct Y-chromosome was observed at prophase after staining with orcein, CMA, and DAPI. The Y-chromosomes were fully fluoresced with both CMA and DAPI, revealing the tandem existence of GC- and AT-rich repeats along the length. The most striking feature is that the Y-chromosome with distinct centromeres was observed even in the interphase nuclei and prophase stages after orcein, CMA, and DAPI staining. It suggested that the Y-chromosomes contracted much earlier than those of autosomes. This feature of the Y-chromosome has not yet been reported and is a new unique feature of Y-chromosomes of C. grandis. Different types of CMA- and DAPI-banding patterns were found in male and female plants, which are characteristic features of each sex. The difference of GC- and AT-rich percentage was due to the Y-chromosome. Four different primers were used for RAPD profiling. Polymorphism of RAPD bands was distinct in male and female plants. Therefore, the compilation of the above information will be very useful for making multidimensional genetic information of male and female C. grandis L. found in Bangladesh.
\end{abstract}

Key words Fluorescent banding, Karyotype, RAPD, Coccinia grandis L.

Coccinia grandis L. is a dioecious, perennial and herbaceous climber, belonging to the family Cucurbitaceae. It is commonly known as ivy gourd, growing wildly in many tropical and subtropical regions in Asia. In Bangladesh, this species is common throughout the country.

Coccinia grandis L. has an active XX-XY system of sex determination with male heterogametic and morphologically distinguishable sex chromosomes. Both male and female plants have equal medicinal importance (Vadivu et al. 2008, Rao et al. 2003). Due to its medicinal importance, the plant has long been used as traditional medicine by the local people of Bangladesh. As a consequence, the plant is now under threat. Scientists are paying attention to conserve and to create awareness about the proper use of this plant. Before conservation, genetic information of a plant is essential (Nass 2001). It is very important to know whether the plant is conserved with complete genetic information. Otherwise, the conservation will not be meaningful.

Karyotype analysis is one of the methods that provide

\footnotetext{
* Corresponding author, e-mail: ssalam81@yahoo.com

DOI: $10.1508 /$ cytologia. 81.349
}

basic genomic information (Khatun and Alam 2010, Khatun et al. 2011). Karyotype is a stable character specific to each specimen. Except for a few reports on the $2 n$ chromosome number, detailed karyotype information about Coccinia species is not available. Previously, few workers studied the mitotic chromosomes of Coccinia grandis L. (Chakravorti 1948, Kumar and Viseveshwaraiah 1952). These studies were mainly based on determination of the basic chromosome number and identification of the X-Y-chromosome pair in meiosis (Sousa et al. 2013). Karyotype and genome size of plant species provide authentic information, which is useful in the systematic evolution and conservation of plants (Guerra 2008), especially in taxa with smaller chromosomes like Coccinia (Skornicková et al. 2007). A quick perusal of published literature reveals that somatic chromosome numbers have been investigated in various species of Coccinia and polyploidy has been implicated in the diversification and evolution of the species (Chakravorti 1948, D'Cruz et al. 1972, Roy and Roy 1971, Sen and Datta 1977).

The conventional karyotype analysis alone is unable to express the differences among different germplasms 
of a species since the germplasms of a species possess similar $2 n$ chromosome numbers and even other karyotype parameters (Khatun and Alam 2010, Khatun et al. 2011). Moreover, the consideration of chromosome length, arm ratio, position, and number of secondary constrictions are not always sufficient to differentiate individual chromosomes. Minute deletion, inversion, tandem duplication, etc. cannot be detected by conventional karyotype analysis. In such cases, some modern cytogenetical techniques are necessary for comparative study among different germplasms of a species.

Staining with DNA-base specific banding with fluorochromes such as chromomycin $\mathrm{A}_{3}$ (CMA) and 4',6-diamidino-2-phenylindole (DAPI) is a relatively recent method for karyotype study. Schweizer (1976) for the first time initiated this technique. CMA binds with GC (Guanine-Cytosine)-rich repetitive sequences of the genome and gives characteristic yellow color bands. On the other hand, DAPI binds to AT (Adenine-Thymine)rich repeats giving the characteristic blue color (Schweizer 1976, Alam and Kondo 1995, Kondo and Hizume 1982, Jessy et al. 2005, Akhter and Alam 2005, Islam and Alam 2011, Sultana et al. 2011). Thus it seems that fluorescent banding is quite satisfactory for detailed and critical chromosome analysis such as identification of individual chromosomes, determination of amount and site of AT- and GC-rich base pairs in chromosomes, etc.

Molecular marker analysis has become another important tool in studying genetic information and diversity (Bered et al. 2005). The utility of molecular markers is generally determined by the technology that is used to reveal DNA-based polymorphisms. DNA fingerprinting by Random Amplified Polymorphic DNA (RAPD) is one of the molecular methods for characterizing different plant specimens. The term DNA fingerprinting/ profiling describes the combined use of several single locus detection systems. This method has been used as a versatile tool for investigating various genomic aspects of an organism. It includes characterization of genetic variability, genome fingerprinting, genome mapping, gene localization, analysis of genome evolution, population genetics, taxonomy etc. The advantages of RAPD analysis over other methods are its low sample DNA requirement and the high frequency of polymorphic bands detected (Williams et al. 1990).

Although a few cytological works has been carried out in this species (Chakravorti 1948, D'Cruz et al. 1972, Roy and Roy 1971, Sen and Datta 1977), no combined research on cytogenetical and molecular analysis has been undertaken. The multiple lines of research viz. conventional karyotype, differential chromosome banding, staining property of interphase nuclei, and prophase chromosomes together with RAPD analysis, will provide multidimensional genetic information of male and female plants helpful for proper conservation of this important medicinal plant.
Therefore, in the present study, a combination of cytogenetical and molecular analysis was carried out for the first time to characterize male and female Coccinia grandis plants from Bangladesh with the following aims:

i. To compare the staining property of the interphase nuclei and prophase chromosomes of both male and female plants after staining with orcein and CMA and DAPI.

ii. To make the conventional orcein-stained karyotype of male and female Coccinia grandis plants.

iii. To compare the fluorescent banding pattern after staining with CMA- and DAPI- fluorochromes.

iv. To compare RAPD banding patterns.

v. To compile the above information for making multidimensional genetic information of male and female C. grandis found in Bangladesh.

\section{Materials and methods}

Two sexes of Coccinia grandis L. were collected from the rural area near Savar of Dhaka district and maintained in the Botanical garden, Department of Botany, University of Dhaka.

\section{Cytogenetical study}

Healthy roots were collected and pretreated with 8-hydroxyquinoline $(0.002 \mathrm{M})$ for $1.5 \mathrm{~h}$ at $20-25^{\circ} \mathrm{C}$ followed by $15 \mathrm{~min}$ fixation in $45 \%$ acetic acid at $4^{\circ} \mathrm{C}$. These were then hydrolyzed in a mixture of $1 \mathrm{~N} \mathrm{HCl}$ and $45 \%$ acetic acid $(2: 1)$ at $60^{\circ} \mathrm{C}$ for $30 \mathrm{~s}$. The root tips were stained and squashed in $1 \%$ aceto-orcein. For CMA- and DAPI banding, Alam and Kondo's (1995) method was used with slight modification. After hydrolysing and dissecting, the materials were squashed with $45 \%$ acetic acid. The cover glasses were removed quickly on dry ice and allowed to air dry for at least $24 \mathrm{~h}$ before the study. The air-dried slides were first pre-incubated in McIlvaine's buffer $(\mathrm{pH} 7.0)$ for $30 \mathrm{~min}$ followed by Distamycin A $\left(0.1 \mathrm{mg} \mathrm{mL}^{-1}\right)$ treatment for $10 \mathrm{~min}$. The slides were rinsed mildly in McIlvaine's buffer supplemented with $\mathrm{MgSO}_{4}(5 \mathrm{mM})$ for $15 \mathrm{~min}$. One drop of CMA $\left(0.1 \mathrm{mg} \mathrm{mL}^{-1}\right)$ was added to the materials for $15 \mathrm{~min}$ in a humid chamber and then rinsed with McIlvaine's buffer with $\mathrm{MgSO}_{4}$ for $10 \mathrm{~min}$. Slides were mounted in $50 \%$ glycerol and kept at $4{ }^{\circ} \mathrm{C}$ overnight before observation. These were observed under a Nikon (Eclipse 50i) fluorescent microscope with the blue violet (BV) filter cassette. For DAPI-staining, after $24 \mathrm{~h}$ of air drying, the slides were first pre-incubated in McIlvaine's buffer ( $\mathrm{pH} 7.0$ ) for $27 \mathrm{~min}$ and treated in Actinomycin $\mathrm{D}\left(0.25 \mathrm{mg} \mathrm{mL}^{-1}\right)$ for $10 \mathrm{~min}$ in a humid chamber. The slides were immersed in DAPI solution $\left(0.01 \mathrm{mg} \mathrm{mL}^{-1}\right)$ for $20 \mathrm{~min}$ and mounted with $50 \%$ glycerol. These were observed under a Nikon (Eclipse 50i) fluorescent microscope with the ultra violet (UV) filter cassette. 


\section{DNA isolation}

Leaves were harvested and total genomic DNA was extracted by using a modified CTAB method (Doyle and Doyle 1987). DNA concentration was quantified through a spectrophotometer (Analylikjena, Specord 50, Germany). The A 260/280 readings for DNA samples were $1.6-1.8$.

\section{PCR amplification and primer survey}

The PCR reaction mixture of $25 \mu \mathrm{L}$ contained $2 \mu \mathrm{L}$ template DNA $(25 \mathrm{ng}), 18.8 \mu \mathrm{L}$ de-ionized distilled water, $2.5 \mu \mathrm{L}$ Taq buffer A $10 \times$ (Tris with $15 \mathrm{mM}$ $\left.\mathrm{MgCl}_{2}\right), 1.0 \mu \mathrm{L}$ primer $(10 \mu \mathrm{M}), 0.5 \mu \mathrm{L}$ dNTPs $(2.5 \mathrm{mM})$, and $0.2 \mu \mathrm{L}$ Taq DNA polymerase $\left(5 \mathrm{U}_{\mu} \mathrm{L}^{-1}\right)$. PCR amplification was done in an oil-free thermal cycler (Biometra UNOII, Germany) for 46 cycles after initial denature at $94^{\circ} \mathrm{C}$ for $5 \mathrm{~min}$, denature at $94^{\circ} \mathrm{C}$ for $1 \mathrm{~min}$, annealing at $34-36^{\circ} \mathrm{C}$ for $30 \mathrm{~s}$, extension at $72^{\circ} \mathrm{C}$ for $3 \mathrm{~min}$, and final extension at $72^{\circ} \mathrm{C}$ for $5 \mathrm{~min}$. Five random primers including OPA-6 (5'-GGT CCC TGA C-3'), OPA-10 (5'-GTG ATC GCA G-3'), primer-1 (5'-GAA ACG GGT G-3') and primer-23 (5'-GTC AGG GCA A-3') were used in the present study for screening.

\section{Gel electrophoresis}

The amplified products were separated electrophoretically on $1 \%$ agarose gel. The gel was prepared using $1.0 \mathrm{~g}$ agarose powder containing $8 \mu \mathrm{L}$ ethidium bromide $\left(10 \mathrm{mg} \mathrm{mL}^{-1}\right)$ and $100 \mathrm{~mL} 1 \times \mathrm{TAE}$ buffer. Agarose gel electrophoresis was conducted in $1 \times$ TAE buffer at $50 \mathrm{~V}$ and $100 \mathrm{~mA}$ for $1.5 \mathrm{~h}$. DNA ladder $(1 \mathrm{~kb})$ was electrophoresed alongside the RAPD reactions as marker. DNA bands were observed on a UV-transilluminator and photographed by a gel documentation system.

\section{Scoring and data analysis}

The PCR products were analyzed after gel electrophoresis. The photographs were critically discussed on the basis of presence (1) or absence (0), size of bands, and overall polymorphism of bands.

\section{Results and discussion}

\section{Conventional karyotype}

In both male and female plants, 24 chromosomes in the diploid complement were observed in every cell (Figs. 2, 7, 19, 20). A similar diploid chromosome number was reported earlier by different workers (Bhaduri and Bose 1947, Chakravorti 1948, Sousa et al. 2013, Bhowmick et al. 2012). However, Bhowmick et al. (2012) reported variant chromosome numbers ranging from 22 to 78 chromosomes per cell (1.91\%) in the female plant, while in the male plants about $2.21 \%$ cells showed variant chromosome numbers ranging from 21 to 43 chromosomes. Kumar and Viseveshwaraiah (1952) and Guha et al. (2004) reported variations in the diploid chromosome number in the somatic cells in both sexual forms of this species. The reason for these chimeric cells was unknown. This may be due to either i) non-disjunction/preferential distribution of several chromosomes at anaphase or ii) probable presence of B-chromosome. However, one thing is clear; the origin of chimeric cells was independent of sex. In the present study, over 50 well spread cells in both male and female were observed in detail. No variation in chromosome number was found in any cell of both male and female plants. Therefore, the plant samples (male and female) collected from Bangladesh possessed 24 chromosomes in the diploid cells without any variation.

In this study, chromosomes of both male (including the Y-chromosome) and female were metacentric (Figs. 10, 22, Table 1). Metacentric chromosomes in the male and female $C$. grandis were also reported by Sousa et al. (2013). On the other hand, Bhowmick et al. (2012) reported submedian and subterminal chromosomes in addition to frequent median to nearly median chromosomes. There are two probable reasons for this disagreement regarding centromeric position: (i) the chromosomes of Coccinia grandis were too minute to detect the centromere clearly and (ii) different authors used different procedures for the classification of chromosomes based on centromeric position.

In this research work, the length of individual chromosomes ranged from 0.97 to $5.03 \mu \mathrm{m}$ (Y-chromosome) in the male plant and 0.78 to $1.32 \mu \mathrm{m}$ in the female plant (Table 1). Bhowmick et al. (2012) reported 1.28 to $4.00 \mu \mathrm{m}$ (Y-chromosome) in the male and 1.32 to $2.15 \mu \mathrm{m}$ in the female plant. On the other hand, Sousa et al. (2013) stated a range of 1.33 to $4.71 \mu \mathrm{m}$ in the male and 1.35 to $2.26 \mu \mathrm{m}$ in the female plant. The ranges described by the earlier workers were similar; however, the range of the present study was a bit smaller than those reported earlier. This might be due to the measurement of metaphase chromosomes at different contraction in metaphase.

The total chromatin length (TCL) was found to be $32.66 \mu \mathrm{m}$ and $25.05 \mu \mathrm{m}$ in the male and female plants, respectively (Table 1). Excluding the length of Y-chromosome, the TCL of male and female plants are almost similar, i.e., the length of Y-chromosome makes a difference in TCL between male and female plants. Sousa et al. (2013) reported similar observations. In contrast, Bhowmick et al. (2012) reported TCL $40.64 \mu \mathrm{m}$ in male and $39.70 \mu \mathrm{m}$ in female, i.e., the difference was about $1.0 \mu \mathrm{m}$. This result of Bhowmick et al. (2012) revealed that excluding the length of the Y-chromosome, the TCL of male was less than that of female. Therefore, the findings reported by Bhowmick et al. (2012) were different from the present finding and the findings of Sousa et al. (2013) with respect to TCL. 

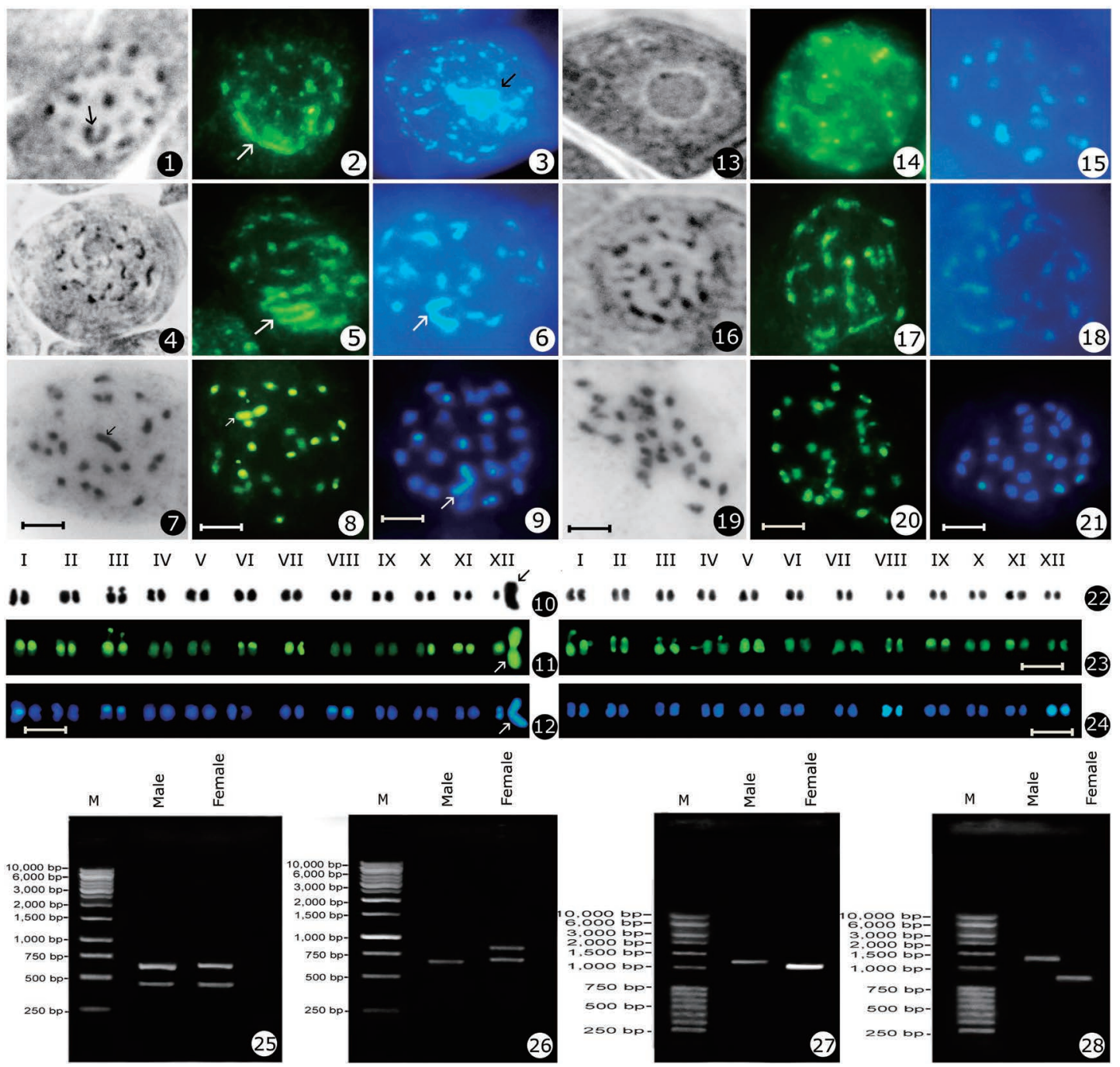

Figs. 1-28. Orcein-, CMA- and DAPI-stained different mitotic stages and RAPD analysis of male and female Coccinia grandis L. 1. Orcein-stained interphase nuclei of male plants. 2. CMA-stained interphase nuclei of male plants. 3. DAPIstained interphase nuclei of male plants. 4. Orcein-stained prophase chromosomes of male plants. 5. CMA-stained prophase chromosomes of male plants. 6. DAPI-stained prophase chromosomes of male plants. 7. Orcein-stained metaphase chromosomes of male plants. 8. CMA-stained metaphase chromosomes of male plants. 9. DAPI-stained metaphase chromosomes of male plants. 10. Orcein-karyotype of male plants. 11. CMA-karyotype of male plants. 12. DAPI-karyotype of male plants. 13. Orcein-stained interphase nuclei of female plants. 14. CMA-stained interphase nuclei of female plants. 15. DAPI-stained interphase nuclei of female plants. 16. Orcein-stained prophase chromosomes of female plants. 17. CMA-stained prophase chromosomes of female plants. 18. DAPI-stained prophase chromosomes of female plants. 19. Orcein-stained metaphase chromosomes of female plants. 20. CMAstained metaphase chromosomes of female plants. 21. DAPI-stained metaphase chromosomes of female plants. 22. Orcein-karyotype of female plants. 23. CMA-karyotype of female plants. 24. DAPI-karyotype of female plants. Bar $=5 \mu \mathrm{m}$, arrows indicate Y-chromosome, 25. RAPD with primer OPA-6. 26. RAPD with primer OPA-10. 27. RAPD with primer-1. 28. RAPD with primer-23.

\section{Secondary constriction and satellite}

In the present research, a pair of satellites was observed, one in each member of pair III, and only in male plants. The satellite was prominent, easily detectable, and $0.34 \mu \mathrm{m}$ in length. No satellite or secondary constriction was found in the female plant (Figs. 10, 22, Table 1). Bhowmick et al. (2012) reported a pair of satellites in both male and female plants. In contrast, no satellite was found in any sex by Sousa et al. (2013). The comparative results revealed that the satellite portion might be deleted from the respective chromosomes of samples used by previous authors.
In male plants, after CMA staining, a pair of satellites was found in pair III similar to when stained with orcein (Fig. 11). In contrast, three pairs of satellites were found in pair I, III, and IV of female plants (Fig. 23). On the other hand, no satellite was found in male or female plants after DAPI staining (Figs. 12, 24), suggesting the CMA positive and DAPI negative nature of satellites. Since CMA binds to GC-rich and DAPI binds to AT-rich repeats of chromosomes, the above reversible banding pattern revealed absolute GC-richness of the satellite portions (Schweizer 1976, Alam and Kondo 1995, Alam et al. 1996, Sultana and Alam 2007, Khatun and Alam 
Table 1. Comparative orcein-, CMA- and DAPI- karyotype analysis of male and female plants of Coccinia grandis L.

\begin{tabular}{|c|c|c|c|c|c|c|c|c|c|c|}
\hline $\begin{array}{c}\text { Coccinia } \\
\text { plant }\end{array}$ & $2 n$ & $\begin{array}{c}\text { Range of } \\
\text { chromosomal } \\
\text { length }(\mu \mathrm{m})\end{array}$ & $\begin{array}{l}\text { Total length of } \\
2 n \text { chromosome } \\
\text { complement }(\mu \mathrm{m})\end{array}$ & $\begin{array}{l}\text { Centromeric } \\
\text { formulae }\end{array}$ & $\begin{array}{l}\text { No. of } \\
\text { CMA- } \\
\text { bands }\end{array}$ & $\begin{array}{l}\text { Total length of } \\
\text { CMA-banded } \\
\text { region }(\mu \mathrm{m})\end{array}$ & $\begin{array}{l}\% \text { of } \\
\text { GC-rich } \\
\text { repeats }\end{array}$ & $\begin{array}{l}\text { No. of } \\
\text { DAPI } \\
\text { bands }\end{array}$ & $\begin{array}{l}\text { Total length of } \\
\text { DAPI-banded } \\
\text { region }(\mu \mathrm{m})\end{array}$ & $\begin{array}{l}\% \text { of } \\
\text { AT-rich } \\
\text { repeats }\end{array}$ \\
\hline Male & 24 & $0.97-5.03$ & 32.66 & $24 m$ & 15 & 15.92 & 48.70 & 7 & 6.73 & 20.60 \\
\hline Female & 24 & $0.78-1.32$ & 25.05 & $24 \mathrm{~m}$ & 16 & 11.77 & 47.00 & 4 & 4.37 & 17.40 \\
\hline
\end{tabular}

$\mathrm{m}=$ metacentric chromosomes.

\section{0, Khatun et al. 2011).}

In female plants, no satellite was found in orcein staining whereas three pairs were observed after CMA staining (Figs. 22, 23). This was the most unexpected finding. Alam and Kondo (1995) reported some stain specific satellites and chromosomal segments in Drosera species after a sequential staining with orcein, Giemsa C-banding, CMA, and DAPI. They found that some satellites and segments were observed in some stains and not in others. The satellite of female plants of $C$. grandis might have stain specificity, as we observed in CMA staining but not with orcein. Therefore, the satellites of C. grandis were GC-rich and stain specific as well.

\section{Fluorescent staining}

Different types of CMA banding patterns were found in both male and female plants. Most of the chromosomal parts were stained brightly with CMA in male and female plants (Figs. 6, 18). In the female plant, two pairs of chromosomes had terminal bands on both ends (Figs. $18,23)$. The Y-chromosome in the male plant fluoresced along the entire length (Figs. 5, 6, arrow). CMA bands represented GC-rich repeats in chromosomes (Schweizer 1976). About 48.7 and $47 \%$ GC-rich area were found in male and female plants, respectively (Table 1). The difference of percentage of GC-rich area was due to the Ychromosome since this chromosome fluoresced entirely with CMA. Bhowmick et al. (2012) carried out CMA banding in both male and female plants. They found that most of the bands were present at the centromeric region of chromosomes suggesting the occurrence of GC-rich repeats to the centromeric region. In this study, no centromeric CMA band was observed in male and female plants (Figs. 6, 11, 18, 23), rather, thick fluorescence was found that occupied most of the chromosomal parts and thus showed different CMA banding rather than those of Bhowmick et al. (2012).

On the other hand, only six and four chromosomes of male and female plants showed DAPI banding, respectively (Figs. 9, 12, 21, 24). In male plants, X, Y, and a member of pair VIII fluoresced brightly with DAPI while the other bands were at the terminal regions (Figs. 9, 12, arrow). In the female plant, two pairs of chromosomes (pair VIII and XII) were fluoresced entirely (Figs. 21, 24). DAPI fluorescence represented AT-rich repeats in the chromosomes (Schweizer 1976), thus the AT-rich repeats were present at the terminal and along the length of chromosomes in the male and only along the length of four chromosomes in the female plants. Bhowmick et al. (2012) did not observe any DAPI band in male and female plants. All the chromosomes were weakly fluoresced with DAPI revealing the lack of AT-rich repeats in the chromosomes of their samples.

Although the chromosomes of the male and female plants were morphologically similar except the Y-chromosomes, differences could be traced out in the number of chromosomes producing particular types of CMA and DAPI signals. Till now, the only chromosomal character used to distinguish between male and female plants was the occurrence of Y-chromosome in male. As per the present observation, the variation in CMA and DAPI banding pattern in chromosomes may be utilized as another level of cytogenetic distinction between male and female $C$. grandis L.

Moreover, the differences of fluorescent banding pattern between the samples of Coccinia grandis from Bangladesh and abroad indicating the genomic reshuffling among them.

\section{Nature of Y-chromosome}

The Y-chromosome of $C$. grandis found in this study was $5.03 \mu \mathrm{m}$ long, which is about 3.06 times bigger than the largest autosome (Table 1). Sousa et al. (2013) reported that the Y-chromosome was 2.06 times larger than the largest autosome while according to Bhowmick et al. (2012), it was less than two times larger than the largest autosome. The length of Y-chromosome measured in this study was about $1 \mu \mathrm{m}$ longer than the previous reports. On the other hand, 2.5 times and 3-4 times larger Y-chromosomes were reported by the earlier workers (Bhaduri and Bose 1947, Guha et al. 2004). Therefore, the above results suggest the presence of different sized Y-chromosomes in C. grandis $\mathrm{L}$.

There are several opinions regarding the heteromorphic sex chromosomes in plants. Hizume et al. (1988) reported that in Podocarpus macrophyllus, females have 38 telocentric chromosomes while males have 36 telocentric and one large sub-metacentric chromosomes. In meiosis, the Y-chromosome paired with two telocentric chromosomes to form a trivalent, suggesting it may have originated from a telocentric fusion of two telocentric chromosomes.

Grabowska-Joachimiak et al. (2011) suggested that a terminal fusion event lead to the reduction of the 
Table 2. Compilation of RAPD analysis in male and female plants of Coccinia grandis L.

\begin{tabular}{|c|c|c|c|c|c|}
\hline Primer codes & Size ranges $(b p)$ & Total bands & Germplasm-specific unique bands (bp) & Common bands (bp) & Polymorphisms (\%) \\
\hline OPA-6 & $400-650$ & 2 & - & $2(650,400)$ & - \\
\hline OPA-10 & $700-800$ & 2 & 1 (800 bp in female plant) & $1(700$ bp) & 50.00 \\
\hline Primer-1 & $1000-1200$ & 2 & $\begin{array}{l}1 \text { (1000 bp in female plant) } \\
1 \text { (1200 bp in male plant) }\end{array}$ & - & 100.00 \\
\hline Primer-23 & $850-1300$ & 2 & $\begin{array}{l}1 \text { ( } 850 \text { bp in female plant) } \\
1 \text { (1300 bp in male plant) }\end{array}$ & - & 100.00 \\
\hline Grand total: & $400-1300$ & 8 & 5 & 1 & 62.50 \\
\hline
\end{tabular}

chromosome number and formation of Y-chromosome in Humulus japonicas. In Silene latifolia, telomere homologous sequences on the sex chromosomes provided evidence of a translocation of subtelomeric sites (Uchida et al. 2002). However, Sousa et al. (2013) did not find any telomeric sequences at interstitial regions after fluorescent in situ hybridization (FISH), suggesting that such fusion have not contributed to the elongation of Ychromosome of $C$. grandis unlike other plants.

The large size Y-chromosome indicated the possibility of accumulation of repeated sequences, which is a sign of evolution of plant Y-chromosomes (Jamilena et al. 2008, Bergero et al. 2008, Heslop-Harrison and Schwarzacher 2011, Mariotti et al. 2009). Moreover, Sousa et al. (2013) reported that the subterminal repetitive sequences may have accumulated on the Y-chromosomes. In the present study, the Y-chromosomes were fully fluoresced with both CMA and DAPI, revealing the tandem existence of GC- and AT rich repeats along the length. Therefore, the size difference of Y-chromosomes between the present samples and earlier samples was due to (i) either asynchronous repetition of GC- and AT-rich bases or (ii) deletion of some chromosomal parts. Since the Y-chromosomes are mostly heterochromatic (Sousa et al. 2013), there was no impact of repetition and deletion of chromosomal segment from the Y-chromosomes of the male plants.

In this study, except for a prominent primary constriction at the middle, no other constriction was found on Y-chromosomes. No secondary constriction on the Y-chromosome was reported earlier (Guha et al. 2004, Sousa et al. 2013). However, Bhowmick et al. (2012) reported two constrictions, one near the centre and the other subterminal on the Y-chromosome of $C$. grandis. They found that the Y-chromosome attached to the nucleolus at diakinesis, suggesting the involvement of this chromosome in organizing the nucleolus. In this study, a persistent nucleolus was found in metaphase and prophase stages (Figs. 5-9). The Y-chromosome was found aloof from the nucleolus. Moreover, Sousa et al. (2013) could not detect an rDNA site on the Y-chromosome. Therefore, the Y-chromosome found in this study and by Sousa et al. (2013) was not involved in organizing the nucleolus.

In the present work, the most striking feature is that the Y-chromosome with distinct centromeres was observed even in the interphase nuclei and prophase stages after orcein, CMA, and DAPI staining (Figs. 1-6, arrow). Generally, the chromosomes at interphase do not have any structure. These remain as chromatins in the interphase nuclei. In prophase, thin, elongated and highly coiled chromosomes appeared where centromeres and other parts are indistinguishable. At metaphase, the chromosomes are most contracted and clearly visible. However, in this study, Y-chromosomes at interphase and prophase stage have almost similar size to that of metaphase. It suggested that the Y-chromosomes contracted much earlier than those of autosomes. This feature of the Y-chromosome has not yet been described and is a new feature of Y-chromosome of $C$. grandis.

\section{RAPD analysis}

Four different primers were used for RAPD profiling. Only one to two bands were found in each primer. Although the numbers of bands were less, these were thick, bright and prominent. Polymorphism of RAPD bands was distinct in male and female plants (Figs. 26-28). The polymorphism was $100 \%$ with primer-1 and primer-23 (Table 2). High rate of polymorphism indicated maximum genomic dissimilarity. The experiment was repeated with the same primer and the bands were found to be stable. Therefore, the RAPD polymorphism with these primers is a new approach, which could be applied to distinguish male and female plants of $C$. grandis especially at their vegetative stages.

\section{Conclusion}

Therefore, the compilation of the cytogenetical and molecular information will be very useful for making multidimensional genetic information of male and female C. grandis found in Bangladesh.

\section{Acknowledgements}

This research was partly supported by a Grant from the Ministry of Science and Technology, People's Republic of Bangladesh (2014-15/BS-94/527) and Centre for Advanced Studies and Research in Biological Sciences, University of Dhaka (Research Grant for 2014-2015 
fiscal year).

\section{References}

Akhter, S. and Alam, Sk. S. 2005. Differential fluorescent banding pattern in three varieties of Cicer arietinum L. (Fabaceae). Cytologia 70: 441-445.

Alam, Sk. S. and Kondo, K. 1995. Differential staining with Orcein, Giemsa, CMA, and DAPI for comparative chromosome study of 12 species of Australian Drosera (Droseraceae). Am. J. Bot. 82: $1278-1286$.

Alam, Sk. S., Kondo, K. and Hoshi, Y. 1996. Study on diffused centromeric nature of Drosera chromosome. Cytologia 60: 43-47.

Bered, F., Terra, T. F., Spellmeier, M. and Neto, J. F. B. 2005. Genetic variation among and within sweet corn populations detected by RAPD and SSR markers. Crop Breed. Appl. Biotech. 5: 418-425.

Bergero, R., Forrest, A. and Charlesworth, D. 2008. Active miniature transposons from a plant genome and its nonrecombining $\mathrm{Y}$ chromosome. Genetics 178: 1085-1092.

Bhaduri, P. and Bose, P. 1947. Cyto-genetical investigations in some common cucurbits, with special reference to fragmentation of chromosomes as a physical basis of speciation. J. Genet. 48: 237-256.

Bhowmick, B. K., Jha, T. B. and Jha, S. 2012. Chromosome analysis in the dioecious cucurbit Coccinia grandis (L.). Voigt. Chromosome Sci. 15: 9-15.

Chakravorti, A. K. 1948. Cytology of Coccinia indica W. \& A. with reference to the behaviour of its sex-chromosomes. Proc. Ind. Acad. Sci. Sec. B 27: 74-86.

D’Cruz, R., Vyahalkar, G. R. and Ugale, S. D. 1972. Cytogenetic studies in tetraploid Coccinia indica W. and A. Caryologia G. Citol. Citosistematica Citogenet. 25: 505-512.

Doyle, J. J. and Doyle, J. L. 1987. A rapid DNA isolation procedure for small quantities of fresh leaf tissues. Phytochem. Bull. 19: $11-15$.

Grabowska-Joachimiak, A., Mosiolek, M., Lech, A. and Góralski, G. 2011. C-banding/DAPI and in situ hybridization reflect karyotype structure and sex chromosome differentiation in Humulus japonicus Siebold \& Zucc. Cytogenet. Genome Res. 132: 203-211.

Guerra, M. 2008. Chromosome numbers in plant cytotaxonomy: Concepts and implications. Cytogenet. Genome Res. 120: 339-350.

Guha, A., Sinha, R. K. and Sinha, S. 2004. Average packing ratio as a parameter for analyzing the karyotypes of dioecious cucurbits. Caryologia G. Citol. Citosistematica Citogenet. 57: 117-120.

Heslop-Harrison, J. S. and Schwarzacher, T. 2011. Organisation of the plant genome in chromosomes. Plant J. 66: 18-33.

Hizume, M., Tominaga, K. and Tanaka, A. 1988. Fluorescent chromosome banding in Larix leptolepis (Pinaceae). Bot. Mag. Tokyo 101: $333-336$

Islam, M. and Alam, Sk. S. 2011. Karyotype characterization with fluorescent banding in one released and two wild germplasms of Hibiscus cannabinus L. Cytologia 76: 223-227.

Jamilena, M., Mariotti, B. and Manzano, S. 2008. Plant sex chromosomes: Molecular structure and function. Cytogenet. Genome
Res. 120: 255-264.

Jessy, N. S., Begum, R., Khatun, M. and Alam, Sk. S. 2005. Differential fluorescent chromosome banding of four species in Haworthia duval (Aloaceae). Cytologia 70: 435-440.

Khatun, M. and Alam, Sk. S. 2010. Confirmation of species status of Corchorus trilocularis and C. pseudo-olitorius by differential chromosome banding and isozyme assay. Cytologia 75: 83-88.

Khatun, M., Sultana, S. S., Ara, H., Islam, M. N. and Alam, Sk. S. 2011. Differential chromosome banding and isozyme assay of three Corchorus spp. Cytologia 76: 27-32.

Kondo, T. and Hizume, M. 1982. Banding for the chromosomes of Cryptomeria japonica D. Don. J. Jpn. For. Soc. 64: 356-358.

Kumar, L. S. S. and Viseveshwaraiah, S. 1952. Sex mechanism in Coccinia indica Wight and Arn. Nature 170: 330-331.

Mariotti, B., Manzano, S., Kejnovský, E., Vyskot, B. and Jamilena, M. 2009. Accumulation of Y-specific satellite DNAs during the evolution of Rumex acetosa sex chromosomes. Mol. Genet. Genomics 281: 249-259.

Nass, L. L. 2001. Utilização de Recursos Genéticos Vegetais no Melhoramento. In: Nass, L. L., Valois, A. C. C., Melo, I. S., Valadares-Inglis, M. C. and Fundação, M. T. (eds.). Recursos Genéticos e Melhoramento-Plantas. Rondonópolis. pp. 29-56.

Rao, G. M. M., Vijayakumar, M., Rao, C., Rawat, A. K. S. and Mehrotra, S. 2003. Hepatoprotective effect of Coccinia indica against $\mathrm{CCl}_{4}$ induced hepatotoxicity. Nat. Prod. Sci. 9: 13-17.

Roy, R. P. and Roy, P. M. 1971. Mechanism of sex determination in Coccinia indica. J. Indian Bot. Soc. 50: 391-400.

Schweizer, D. 1976. Reverse fluorescent chromosome banding with chromomycin and DAPI. Chromosoma 58: 307-324.

Sen, R. and Datta, B. K. 1977. Chromosomal basis of sex expression in some dioecious cucurbits. Nucleus 22: 241.

Skornicková, J. L., Sída, O., Jarolimová, V., Sabu, M., Fér, T., Trávnicek, P. and Suda, J. 2007. Chromosome numbers and genome size variation in Indian species of Curcuma (Zingiberaceae). Ann. Bot. 100: 505-526.

Sousa, A., Fuchs, J. and Renner, S. S. 2013. Molecular Cytogenetics (FISH, GISH) of Coccinia grandis: A ca. 3 myr-old species of Cucurbitaceae with the largest Y/autosome divergence in flowering plants. Cytogenet. Genome Res. 139: 107-118.

Sultana, S. S. and Alam, Sk. S. 2007. Differential fluorescent chromosome banding of Solanum nigrum L. and Solanum villosum L. from Bangladesh. Cytologia 72: 213-219.

Sultana, S. S., Ara, H. and Alam, Sk. S. 2011. Karyotype analysis with orcein and CMA in two species of Alocasia (Schott) G. Don (Araceae). Bangladesh J. Bot. 40: 53-56.

Uchida, W., Matsunaga, S., Sugiyama, R., Shibata, F., Kazama, Y., Miyazawa, Y., Hizume, M. and Kawano, S. 2002. Distribution of interstitial telomere-like repeats and their adjacent sequences in a dioecious plant, Silene latifolia. Chromosoma 111: 313-320.

Vadivu, R., Krithika, A., Biplab, C., Dedeepya, P., Shoeb, N. and Lakshmi, K. S. 2008. Evaluation of hepatoprotective activity of the fruits of Coccinia grandis Linn. Int. J. Health Res. 1: 163-168.

Williams, J. G. K., Kubelik, A. R., Livak, K. J., Rafalski, J. A. and Tingey, S. V. 1990. DNA polymorphisms amplified by arbitrary primers are useful as genetic markers. Nucleic Acids Res. 18: $6531-6535$. 